\title{
Escritos desobedientes: nuevos actores, nueva escritura
}

\author{
Disobedient writings: new actors, new writing
}

Silvana Mercedes Casali silvana.m.casali@gmail.com

http://orcid.org/0000-0001-7882-1501

Instituto de Estudios Comunicacionales en Medios, Cultura y Poder "Aníbal Ford"; Facultad de Periodismo y Comunicación Social; Universidad Nacional de La Plata/ Consejo Nacional de Investigaciones Científicas y Técnicas (Argentina)

\section{Resumen}

Realizamos la presente reseña a partir de la lectura del libro Escritos desobedientes. Historias de hijas, hijos y familiares de genocidas por la memoria, la verdad y la justicia, publicado en 2018 por la agrupación Historias Desobedientes: familiares de genocidas por la memoria, la verdad y la justicia. El texto narra el surgimiento del colectivo a través de las historias de vida de sus integrantes y de las publicaciones oficiales realizadas en redes sociales y medios de 
comunicación. Consideramos que una de las características más significativas radica en el rasgo colectivo de su escritura.

Palabras clave: Escritos desobedientes; Historias desobedientes; comunicación; política; memoria.

Abstract

We made the present review from the reading of the book Disobedient Writings, published in 2018 by the grouping Disobedient Stories: relatives of genocide by memory, truth and justice. The text narrates the emergence of the collective through the life stories of its members and official publications made in social networks and media. We consider that one of the most significant characteristics lies in the collective trait of his writing.

Keywords: Disobedient writings; Disobedient Stories; communication; politics; memory.

Historias desobedientes es una agrupación que surge en mayo de 2017, como reacción al fallo de la Corte Suprema de Justicia de la Nación que dictaminaba la aplicación del beneficio de la reducción de la pena de prisión efectiva a la mitad de su tiempo -beneficio que se aplica en delitos comunes- para casos de lesa humanidad. El 25 de mayo es la fecha oficial, pero el colectivo ya se venía gestando, por ejemplo, tras la nota publicada en la revista Anfibia a la hija de Migue Etchecolatz (1); en la pregunta de sus propios hijos por el pasado de sus abuelos militares (algunos hoy presos en cárceles comunes); en la decisión política del entonces presidente Néstor Kirchner de reabrir los juicios por crímenes de lesa humanidad en 2006; e incluso en el estallido del 2001: "Ahí hubo un corte con ese miedo y empezamos a salir a la calle", dice una de sus integrantes en Escritos desobedientes, cuya presentación fue realizada el 23 de marzo de este año en el Centro Cultural de la Memoria Haroldo Conti, en vísperas del cuadragésimo tercero aniversario del golpe que dio comienzo a la última dictadura militar. En el acercamiento, la mayoría de las fundadoras del colectivo descubrieron que una de las expresiones más utilizadas por ellas para enfrentar el silencio al que habían sido sometidas desde pequeñas por sus padres y familiares genocidas era la palabra. Primera aclaración: hablamos aquí en femenino porque la mayor parte de las personas que integran el colectivo y escriben y editan el libro que aquí reseñamos son mujeres, y "casualmente" su primera 
aparición pública fue durante una movilización Ni Una Menos, el 3 de junio de 2017. Es, continuando, desde la palabra que cada integrante en su individualidad puede tender puentes con las y los otros para encontrarse primero, para construir la agrupación que las cobija y les da identidad en el espacio de los que reclaman por los derechos humanos y, finalmente, para dar forma a esta creación coral que se materializa en el presente libro. Escritos desobedientes está dividido en dos partes. "Historias de vida" es la primera, y allí encontramos los recorridos individuales de sus actores, con sus inquietudes e incomodidades respecto al accionar de la familia por la que fueron criados, donde predomina el accionar de la figura paterna. Salvo alguna excepción anónima que indica la complejidad de estos procesos y refuerza la importancia del carácter colectivo del libro, se trata de relatos con nombre y apellido que narran recuerdos de infancia y juventud marcados por la mirada militarizada paterna, y el momento en que esto tensiona y desborda la subjetividad de sus protagonistas. Hay relatos biográficos, fragmentos de novelas (publicadas, como La mujer sin fondo, de Stella Duacastella, e inéditas, como la prometedora La habitación incendiada, de Christian Baigorria), crónicas, poesías, cartas, monólogos teatrales y presentaciones en seminarios académicos que han visto la luz en redes sociales (principalmente Facebook y blogs) y en algunos medios de comunicación; pero también nos presentan textos que han sido escritos especialmente para este libro. Es el caso del relato de un hijo de una de las integrantes de este colectivo, quien con diez años narra cómo fue su primera marcha el 24 de marzo bajo la bandera de Historias desobedientes. Como vemos, no sólo estamos ante una agrupación nueva que se expresa en una escritura colectiva, sino que también comienza a asomar la tercera generación: la de los hijos de los hijos.

En la segunda parte, Relatos desobedientes, comienza a tejerse propiamente la trama más colectiva, pues allí aparecen los textos publicados en periódicos y en la cuenta de Facebook de Historias desobedientes. De esta forma, nos vamos encontrando con manifiestos que a la vez que brindan las coordenadas para comprender el surgimiento de la agrupación en el tiempo y en el espacio -en este momento, pero con antecedentes y proyecciones a futuro, acaso una de las más urgentes la modificación de dos artículos del Código Procesal Penal que les impide denunciar y declarar contra sus padres-, también dan cuenta del carácter comunitario del grupo y de la escritura que va narrando su historia. En esta segunda parte el colectivo deja constancia de su reclamo por la desaparición de Santiago Maldonado y luego del pedido de justicia; de la expresión de repudio frente a la prisión domiciliaria otorgada al genocida Miguel Etchecolatz; del rechazo ante la propuesta presidencial de convertir Campo de Mayo en un Parque Nacional o de incluir a las fuerzas armadas en la seguridad interior del país. Si bien Escritos desobedientes viene a sumarse a la extensa producción testimonial, 
periodística, académica y ficcional que aborda la memoria -así como la agrupación se suma a la genealogía de agrupaciones y organismos de derechos humanos que han encabezado la lucha por la memoria, la verdad y la justicia desde el primer momento-, la particularidad de este libro reside en el rasgo colectivo de su escritura. Así, la primera parte con sus historias de vida son textos individuales sólo en su apariencia, pues con el correr de las páginas comprendemos que lo que se está señalando son las simetrías y coincidencias entre los relatos de quienes han sido hijas e hijos de genocidas y que hoy, producto de esas luchas incansables pero también del estado de alerta que se impone frente a los evidentes retrocesos en materia de derechos humanos por parte del gobierno que asumió en 2015, reivindican su politicidad, se nombran públicamente desobedientes a ese pasado de infamia pero también al silencio que en el presente guardan sus padres. "Somos los hijos del silencio que estalla", dice una de las publicaciones en Facebook recopiladas en el libro que nos muestra cómo ellos hablan, narran, producen y publican de manera coral.

Consideramos que nos encontramos ante un hecho histórico, y desde todo punto de vista. En principio, porque el libro desafía la unidimensionalidad de su análisis. Escritos desobedientes podrá ser objeto de la crítica literaria, pero también del campo de la historia, de la filosofía y de la psicología: aquí las fronteras disciplinares estallan.

En segundo lugar, que la mayor parte de las integrantes del libro (y, por extensión, de la agrupación) sean mujeres, habla de un clima de época, pero también de la reivindicación del género que resulta frustrante para las expectativas paternas que esperaban la continuación del imaginario militar en los hijos varones.

En tercer lugar, la singularidad radica en la potencialidad misma de la escritura, práctica que parece haber sido el puente que acercó a los integrantes de la agrupación y que, mediante su carácter performativo, les permitió pensarse en el camino y construir una narración fuerte porque colectiva. Como señalan en el prefacio y en el posfacio Carolina Bartalini y Verónica Estay Stange respectivamente, el gesto político de estos escritos radica en volver público (y político) lo que hasta hace un momento era del ámbito familiar, y desde allí tejer redes colectivas de acción. Lo que irrumpe en la escena pública es un libro que se rebela ante ese mundo privado, que realiza una declaración de principios, y que hace todo ello a partir de una narrativa colectiva. El aporte de Escritos desobedientes no es sólo a las letras o a los estudios de memoria en particular: es a toda la sociedad.

Notas

Question, Vol. 1, N. ${ }^{\circ} 63$, julio-septiembre 2019. ISSN 1669-6581

Instituto de Investigaciones en Comunicación | Facultad de Periodismo y Comunicación Social | Universidad Nacional de La Plata La Plata | Buenos Aires | Argentina

Página 4 de 5 
(1) "Marché contra mi padre genocida". Recuperado de http://revistaanfibia.com/cronica/marche-contra-mi-padre-genocida/

\section{Bibliografía}

Colectivo Historias desobedientes (2018). Escritos desobedientes. Historias de hijas, hijos y familiares de genocidas por la memoria, la verdad y la justicia. Buenos Aires: Marea. 